\title{
Hydrate Nucleation in Quiescent and Dynamic Conditions
}

Sheng Dai, Joo Yong Lee, J. Carlos Santamarina,

\begin{abstract}
Gas hydrate nucleation is the spontaneous formation of an ordered crystalline lattice from a disordered phase. This inherently random process often involves long induction times particularly in quiescent conditions. An experimental study was conducted to explore the kinetics of hydrate formation in the presence of mineral grains and when subjected to mechanical agitation. Results show that tetrahydrofuran THF hydrate nucleation is facilitated in the presence of most minerals, and induction times are a function of mineralogy and surface characteristics. While mechanical vibration does not suppress the inherent stochastic nature of nucleation, mechanical agitation triggers nucleation when the imposed acceleration exceeds $\sim 10 \mathrm{~m} / \mathrm{s}^{2}$.
\end{abstract}

Keywords: hydrate, nucleation, mechanical agitation, interfacial tension 


\section{Introduction}

The nucleation of a new phase is the initial step in water freezing and hydrate formation. The spontaneous formation of an ordered crystalline lattice from a disordered

39 phase is a random process [Mullin, 2001]. In fact, a liquid can be "supercooled" beyond

40 the solid phase equilibrium conditions without experiencing phase transformation. During

41 this metastable state, small crystallites nucleate and immediately break apart. The

42 induction time for decisive crystal growth can vary significantly and may extend for days

43 when gas hydrate forms in quiescent conditions [Sloan and Fleyfel, 1991].

44 Continued crystal growth starts when nuclei exceed a critical size [Mullin, 2001].

45 During phase transformation, the equilibrium temperature can be depressed by ionic 46 concentration or capillary effects, due to the decrease in water activity [Englezo and Hall, 47 1994]. Supercooling, induction time, and equilibrium temperature depression are 48 graphically defined on Figure 1 where the temperature signature corresponds to a fluid 49 that undergoes exothermic phase transition during cooling. While thermodynamic equilibrium conditions can be accurately predicted

51 [Skovborg et al., 1993; Sloan and Koh, 2008], the kinetics of hydrate formation depend 52 on inherently stochastic nuclei formation [Bishnoi and Natarajan, 1996; Natarajan et al., 53 1994; Lee et al., 2013]. Kinetics affects laboratory protocols, flow assurance [Sloan et al., 54 2009], hydrogen storage [Koh et al., 2009], some forms of CO2 sequestration and $55 \mathrm{CO}_{2}-\mathrm{CH}_{4}$ replacement [Tohidi et al., 2010; Jung et al., 2010]. The effects of sediment 56 characteristics and externally imposed vibrations on hydrate nucleation are 57 experimentally investigated in this study. A review of previous studies is presented first. 58 


\section{Previous Studies}

Nucleation is affected by thermal history, the type of solution, the presence and

61 type of impurities, and agitation.

62 (1) Thermal history of the solution: The molecular structure of water that was previously

63 part of hydrate may not be completely disordered when the PT conditions remain near the

64 stability field. This memory effect reduces induction times for hydrate re-formation

65 [Vysniauskas and Bishnoi, 1983]. An order of magnitude increase in the cooling rate

66 lowers the mean nucleation temperature by 0.6 to $2^{\circ} \mathrm{C}$ [Hobbs, 1974].

67 (2) Physical properties of the solution: Viscosity and the amount of available mass affect

68 nucleation and crystal growth [Young and Cross, 1911]. Dissolved salts lower the activity

69 of water through strong coulombic attraction as compared to the weaker hydrogen or Van

70 der Vaals bonds in hydrate structures; lower activity requires lower temperature and

71 higher pressure for phase equilibrium [Englezos and Hall, 1994; Sloan and Koh, 2008].

72 Other biological and polymeric inhibitors effectively hinder nucleation [Al-Adel et al.,

73 2008; Lin et al., 2004].

74 (3) Impurities: The presence of impurities favors heterogeneous nucleation, and reduces

75 both the induction time and the degree of supercooling as a function of particle surface

76 characteristics [Cha et al., 1988; Englezos and Hall, 1994; Riestenberg et al., 2003; Ting

77 and McCabe, 1934]. On the contrary, small pore sizes shift the stability field to higher

78 pressure or lower temperature [Clennell et al., 1999; Fletcher, 1958; Handa and Stupin,

79 1992; Husowitz and Talanquer, 2004; Kwon et al., 2008; Østergaard et al., 2002;

80 Restagno et al., 2000].

81 (4) Mechanical agitation: Experiments show that stirring, shaking, or shocking can 
82 trigger nucleation in a supersaturated fluid [Mullin, 2001; Mullin and Raven, 1962;

83 Skovborg et al., 1993; Young, 1911; Young and Cross, 1911]. Similarly, mechanical

84 stimulation facilitates ice nucleation and gas hydrate formation [Barrer and Edge, 1967;

85 Skovborg et al., 1993; Sloan and Fleyfel, 1991; Tajima et al., 2004]. Experimental results

86 for other systems show that the nucleation rate and the morphology of precipitates are

87 affected by stirring conditions and rate [Akkermans et al., 2006; Liang et al., 2004; Ting

88 and McCabe, 1934].

89

90 3. Experimental Study

Two experimental studies are conducted to investigate the effect of minerals on

92 THF (tetrahydrofuran) hydrate nucleation under quiescent conditions, and to identify the

93 characteristics of mechanical agitation that favor ice and THF hydrate formation. THF

94 provides accurate control on hydrate saturation, overcomes the long diffusion-controlled

95 formation time from aqueous phase, and nucleates at atmospheric pressure; thus THF has

96 been a popular proxy for methane in laboratory studies of hydrate-bearing sediment

97 properties [Lee et al., 2007; Yun et al., 2007]. Devices and test procedures are described 98 first.

99

$100 \quad 3.1$ Experimental devices and configurations

101 Figure 2 illustrates the experimental configurations used for the two studies.

102 Temperature is controlled using a high-precision cooler and measured using a smooth bar

103 K-type thermocouple (precision of $\sim 0.1^{\circ} \mathrm{C}$ ) for both static and dynamic tests. The

104 temperature is measured at the tip of the thermocouple. In dynamic tests (Figure 2b), 
105 external vibrations are supplied through a stainless steel rod $(3.175 \mathrm{~mm}$ in diameter

$106100 \mathrm{~mm}$ in length) coupled to a piezoelectric actuator (Model 712A01, PCB Piezotronics,

107 Inc.). Vibration frequency and amplitude are controlled through the power supply and the

108 rod vibration is measured using a collinearly mounted accelerometer (Model 350B04,

109 PCB Piezotronics, Inc.). The vibration frequency explored in this study ranges from

$110800 \mathrm{~Hz}$ to $7000 \mathrm{~Hz}$, and the amplitude ranges from $1 \mathrm{~nm}$ to $1 \mu \mathrm{m}$.

\section{$112 \quad 3.2$ Materials - Specimen preparation}

113 Specimens for static tests consist of $20 \mathrm{ml} 81 \mathrm{H}_{2} \mathrm{O}: 19 \mathrm{THF}$ solution (stoichiometric 114 solution $-100 \%$ hydrate) and $5 \mathrm{~g}$ of soils. Table 1 summarizes the main properties of the 115 selected soils. The randomly-shaped RP2 kaolinite is smaller than the hexagonal shaped 116 SA1. Crushed silt is angular, low specific surface silt. Precipitated silt consists of silt-size 117 aggregations with extensive inter-particle pore networks which result in high specific 118 surfaces. The irregularly shaped GCC particles are bulkier than the very uniform, 119 rice-shaped PCC particles.

120 The selected soil is added to the solution, shaken vigorously, and left to rest in the 121 sealed cylinder for $1 \sim 2$ hours to allow for sedimentation. A thin layer of oil is added to 122 cover THF solution specimens immediately after mixing to prevent THF evaporation 123 during testing. Each test starts with a freshly prepared specimen to avoid contamination 124 or memory effects.

125 Dynamic tests involve either $10 \mathrm{ml}$ deionized water (ice formation) or $10 \mathrm{ml}$ $12619 \mathrm{H}_{2} \mathrm{O}: 81 \mathrm{THF}$ stoichiometric solution (100\% hydrate formation). 


\subsection{Experimental procedures}

Prepared specimens in test cylinders are sealed and immersed into a cooling bath

130 with a constant temperature of $-5^{\circ} \mathrm{C}$. In dynamic tests, the oscillatory vibration with 131 preselected frequency and amplitude is applied immediately after the cylinder is

132 submerged in the cooler. Bath and specimen temperatures are monitored to detect phase 133 transformation.

\section{$135 \quad 3.4$ Typical temperature signatures}

The equilibrium temperature at the THF hydrate boundary depends on the volume

137 fraction of water and THF (Figure 3a). At atmospheric pressure, the equilibrium 138 temperature of $81 \mathrm{H}_{2} \mathrm{O}: 19 \mathrm{THF}$ solution is $\sim 4.5^{\circ} \mathrm{C}$. Typical temperature-time signatures of 139 deionized water, excess water THF solution $\left(90 \mathrm{H}_{2} \mathrm{O}: 10 \mathrm{THF}\right)$, stoichiometric mixture $140\left(81 \mathrm{H}_{2} \mathrm{O}: 19 \mathrm{THF}\right)$, and excess THF solution $\left(40 \mathrm{H}_{2} \mathrm{O}: 60 \mathrm{THF}\right)$ are shown in Figure $3 \mathrm{~b}$. The 141 induction time in these signatures varies from 3000s (water) to more than 6000s (excess 142 water solution). Supercooling reaches $-7.5^{\circ} \mathrm{C}$ (stoichiometric solution). The exothermic 143 peak readily seen in all cases marks the beginning of the transformation. All reactions 144 reach the equilibrium temperature. The excess water solution exhibits the exothermic 145 peak for hydrate formation followed by the peak for ice formation.

147 4. Results and Analyses

$148 \quad$ 4.1 Heterogeneous hydrate nucleation - Static tests

149 A total of 40 static tests were completed as part of this study. Results are 150 summarized in Figure 4. Measured induction times are log-normally distributed (Note: a 
151 log-normal distribution of induction times was also observed in $\mathrm{CO}_{2}$ hydrate nucleation 152 in Na-montmorillonite suspensions [Lee et al., 2013]). The presence of minerals 153 facilitates nucleation, except in the case of precipitated calcium carbonate PCC. Industrial 154 precipitated mineral (PCC and PS) are less effective at nucleating hydrates than their 155 crushed counterparts (GCC and CS); industrial minerals also exhibit higher water-mineral 156 contact angle.

Mineral surfaces lower the thermal agitation of water molecules, and prompt their 158 alignment; hence, mineral surfaces that more closely mimic the hydrate crystal structure 159 are more efficient nucleators [Blackwell, 1999; Park and Sposito, 2003; Turnbull and 160 Vonnegut, 1952]. The number of water molecules per unit volume next to mineral 161 surfaces $n_{w}\left(1 / \mathrm{m}^{3}\right)$ can be estimated in terms of porosity $n$ and specific surface $S_{s}\left(\mathrm{~m}^{2} / \mathrm{g}\right)$ :

$$
n_{w}=\frac{S_{s}(1-n) G_{s} \rho_{w}}{\left(l_{\text {water }}\right)^{2}}
$$

163 where $G_{s}$ is specific gravity of minerals, $\rho_{\mathrm{w}}$ is water density, and $l_{\text {water }}$ is the characteristic 164 length of a water molecule (estimated $n_{w}$ for each specimen based on the above equation 165 are SA1: $180 / \mathrm{m}^{3}, \mathrm{RP} 2: 145 / \mathrm{m}^{3}$, PS: $600 / \mathrm{m}^{3}, \mathrm{CS}: 0.565 / \mathrm{m}^{3}, \mathrm{GCC}: 9 / \mathrm{m}^{3}$, and PCC: $16649.5 / \mathrm{m}^{3}$ ). Experimental results in Figure 4 do not show clear benefits from specific 167 surface (highest for the two kaolinite clays)., implying that specific surface is less 168 important than other mineral surface characteristics including roughness In fact, the rate 169 of nucleation has been linked to the Gibbs free energy $\Delta G^{*}$, which can be linked to 170 contact and interfacial tension [Hobbs, 1974].

171 Sediment pores can also affect nucleation kinetics in various ways, particularly as 172 pore sizes become smaller than 10nm [Clennell et al., 1999; Handa and Stupin, 1992; 173 Kwon et al., 2008; Østergaard et al., 2002]: nanometer-sized pores restrict embryo size, 
174 water activity is reduced, and capillary suction hinders nucleation (multiphase fluids).

175 Pore sizes in this study are $100 \mathrm{~nm}$ or larger and exert minimal effects on nucleation.

\section{$177 \quad 4.2$ The effect of mechanical vibration on nucleation}

178 The effect of mechanical vibration on nucleation is explored by plotting the data 179 on tripartite plots so that imposed sinusoidal vibration frequency, displacement, velocity, 180 and acceleration are shown at once (Figure 5). The measured data were sorted from short 181 to long induction times, and the boundary between short induction times (crosses) and 182 long induction times (circles) was gradually displaced to attain maximum data 183 discrimination. Results obtained with both water-to-ice and THF solution-to-hydrate 184 transformations show that the boundary from short-to-long induction times is parallel to 185 iso-acceleration lines; thus, acceleration is the best predictor of reduced induction time.

186 A characteristic acceleration threshold is apparent in Figure 5. This is further 187 explored in Figure 6 where induction times are plotted versus peak acceleration. The 188 solid line represents the mean induction time $\mu\left(t_{\text {ind }}\right)$ and dashed lines represent the one 189 standard deviation $\pm \sigma\left(t_{\text {ind }}\right)$ band in induction times measured for specimens without 190 vibration as the control group. The induction time decreases when the peak acceleration 191 exceeds $\sim 10 \mathrm{~m} / \mathrm{s}^{2}$. Histograms of short and long induction times for high and low 192 accelerations show that mechanical vibration does not suppress induction time variability.

193 Hydrate nucleation under quiescent conditions shows decreased induction times and 194 variability (in linear scale) when the system is driven further into stability conditions [Lee 195 et al., 2013].

196 Several hypotheses have been advanced to explain the role of agitation on 
197 nucleation. Some suggest that mechanical agitation enhances nucleation by altering 198 incipient nuclei to favor crystallization sites [Melia and Moffitt, 1964; Mullin and Raven, 199 1962]. Others consider that mechanical agitation causes transient inhomogeneous energy 200 distribution and high energy regions favor nucleation [Mullin, 2001].

201 At the molecular scale, agitation must cause enough relative displacement among 202 neighboring molecules to facilitate nucleation and the formation of a new structure. Let's 203 idealize molecular scale interactions as a damped, single degree of freedom with a linear 204 spring $k$, mass $m$, and dashpot $\eta$. The motion that the second molecular layer experiences $205 y_{m(t)}$ is related to the motion imposed on the first layer $y_{b(t)}=A \cos (\omega t)$ as

$$
y_{m(t)}=H * y_{b(t)},
$$

207 Where the transfer function $H$ represents the intermolecular response function. The 208 equation of motion follows Newton's second law:

$$
m \frac{\partial^{2} y_{m(t)}}{\partial t^{2}}+\eta \frac{\partial\left(y_{m(t)}-y_{b(t)}\right)}{\partial t}+k\left(y_{m(t)}-y_{b(t)}\right)=0 .
$$

210 The combination of Equations 2 and 3 renders:

$$
H=\frac{\omega \eta-k}{\omega^{2} m+\omega \eta-k} .
$$

212 Thus, the maximum relative displacement $\delta$ become

$$
\delta=\left|y_{m(t)}-y_{b(t)}\right|_{\max }=\left|(H-1) y_{b(t)}\right|_{\max }=\frac{A}{1+\frac{\eta}{\omega m}-\left(\frac{\omega_{r}}{\omega}\right)^{2}} .
$$

214 where the resonant frequency $\omega_{r}{ }^{2}=k / m$. The excitation frequencies in this study are 215 much lower than molecular resonance/relaxation frequencies, $\omega / \omega_{\mathrm{r}}<<1$. In this regime, 216 the relative displacement between contiguous molecular layers $\delta / A$ scales with $\omega^{2}$. This is 217 in agreement with experimental results in Figure 5 that show acceleration $a=A \omega^{2}$ as the 
218 key vibration characteristic that affects induction time.

\section{5. Conclusions}

221 Solid phase hydrate formation exhibits induction time, supercooling, and 222 transformation temperature depression. Nucleation is inherently stochastic and 223 experimental results should be expressed in statistical form.

224 The induction time of THF hydrate formation in various types of mineral 225 suspensions follows a log-normal distribution. Nucleation is favored in the presence of 226 most minerals. Mineral surface properties affect the induction time and the degree of 227 supercooling, but do not change the equilibrium temperature during phase transformation. 228 Mineralogy and fluid-mineral interaction (i.e., contact angle and interfacial tension) are 229 more important than particle size and sediment porosity..

230 Mechanical vibration facilitates nucleation but it does not suppress the inherent 231 stochastic nature of nucleation.

232 The tripartite analysis of experimental results reveals that acceleration is a better 233 discriminator between short and long induction times than vibration frequency, amplitude, 234 or velocity. Experimental results suggest that nucleation is prompted when the imposed 235 acceleration exceeds $\sim 10 \mathrm{~m} / \mathrm{s}^{2}$. Relative molecular displacement emerges as the 236 underlying mechanism. Thus, boundary layer shear and pore-scale turbulence in steady 237 sate flow conditions should favor nucleation. 


\section{Acknowledgements}

239 Support for this research was provided by the Joint Industry Project for Methane

240 Hydrate administered by Chevron. Additional funds were from the Goizueta Foundation.

241 We also wish to acknowledge the support of the Korea Institute of Geoscience and

242 Mineral Resources and the Gas Hydrate Research and Development Organization

243 (GHDO) of the Ministry of Knowledge Economy, Republic of Korea. 
Akkermans, C., P. Venema, S. Rogers, A. van der Goot, R. Boom, and E. van der Linden (2006), Shear Pulses Nucleate Fibril Aggregation, Food Biophysics, 1(3), 144-150.

Al-Adel, S., J. A. G. Dick, R. El-Ghafari, and P. Servio (2008), The effect of biological and polymeric inhibitors on methane gas hydrate growth kinetics, Fluid Phase Equilibria, 267(1), 92-98.

Barrer, R. M., and A. V. J. Edge (1967), Gas Hydrates Containing Argon, Krypton and Xenon: Kinetics and Energetics of Formation and Equilibria, Proceedings of the Royal Society of London. Series A. Mathematical and Physical Sciences, 300(1460), 1-24.

Bishnoi, P. R., and V. Natarajan (1996), Formation and decomposition of gas hydrates, Fluid Phase Equilibria, 117(1), 168-177.

Blackwell, V. R. (1999), Formation processes of clathrate hydrates of carbon dioxide and methane, California Institute of Technology.

Cha, S. B., H. Ouar, T. R. Wildeman, and E. D. Sloan (1988), A third-surface effect on hydrate formation, The Journal of Physical Chemistry, 92(23), 6492-6494.

Christiansen, R. L., and E. D. Sloan (1994), Mechanisms and kinetics of hydrate formation, Annals of the New York Academy of Sciences, 715(1), 283-305.

Clennell, B. M., M. Hovland, J. S. Booth, P. Henry, and W. J. Winters (1999), Formation of natural gas hydrates in marine sediments 1 . Conceptual model of gas hydrate growth conditioned by host sediment properties, J. Geophys. Res., 104(B10), 22985-23003.

Englezos, P., and S. Hall (1994), Phase equilibrium data on carbon dioxide hydrate in the presence of electrolytes, water soluble polymers and montmorillonite, The Canadian Journal of Chemical Engineering, 72(5), 887-893.

Fletcher, N. H. (1958), Size Effect in Heterogeneous Nucleation, The Journal of Chemical Physics, 29(3), $572-576$.

Guo, G.-J., Y.-G. Zhang, and H. Liu (2007), Effect of methane adsorption on the lifetime of a dodecahedral water cluster immersed in liquid water: A molecular dynamics study on the hydrate nucleation mechanisms, The Journal of Physical Chemistry C, 111(6), 2595-2606.

Guo, G.-J., Y.-G. Zhang, Y.-J. Zhao, K. Refson, and G.-H. Shan (2004), Lifetimes of cagelike water clusters immersed in bulk liquid water: A molecular dynamics study on gas hydrate nucleation mechanisms, The Journal of chemical physics, 121, 1542.

Handa, Y. P., and D. Y. Stupin (1992), Thermodynamic properties and dissociation characteristics of methane and propane hydrates in 70-.ANG.-radius silica gel pores, The Journal of Physical Chemistry, 96(21), 8599-8603.

Hobbs, P. V. (1974), Ice physics, Clarendon Press.

Husowitz, B., and V. Talanquer (2004), Nucleation in cylindrical capillaries, Journal of Chemical Physics, 121(16), 8021-8028.

Jung, J.W., Espinoza, D.N. and Santamarina, J.C. (2010), Hydrate Bearing Sediments: $\mathrm{CH}_{4}-\mathrm{CO}_{2}$ Replacement, Journal of Geophysical Research, vol. 115, B10102, doi:10.1029/2009JB000812

Koh, C. A., A. K. Sum, and E. D. Sloan (2009), Gas hydrates: Unlocking the energy from icy cages, Journal of applied physics, 106(6), 061101-061101-061114.

Kwon, T.-H., G.-C. Cho, and J. C. Santamarina (2008), Gas hydrate dissociation in sediments: Pressure-temperature evolution, Geochem. Geophys. Geosyst., 9(3), Q03019.

Lee, J. Y., T. S. Yun, J. C. Santamarina, and C. Ruppel (2007), Observations related to tetrahydrofuran and methane hydrates for laboratory studies of hydrate-bearing sediments, Geochem. Geophys. Geosyst., 8, Q06003, doi:10.1029/2006GC001531.

Lee, K., S.-H. Lee, and W. Lee (2013), Stochastic nature of carbon dioxide hydrate induction times in Na-montmorillonite and marine sediment suspensions, International Journal of Greenhouse Gas Control, 14, 15-24.

Liang, K., G. White, D. Wilkinson, L. J. Ford, K. J. Roberts, and W. M. L. Wood (2004), Examination of the Process Scale Dependence of 1-Glutamic Acid Batch Crystallized from Supersaturated Aqueous Solutions in Relation to Reactor Hydrodynamics, Industrial \& Engineering Chemistry Research, 43(5), $1227-1234$.

Lin, W., G. J. Chen, C. Y. Sun, X. Q. Guo, Z. K. Wu, M. Y. Liang, L. T. Chen, and L. Y. Yang (2004), 
Effect of surfactant on the formation and dissociation kinetic behavior of methane hydrate, Chemical Engineering Science, 59(21), 4449-4455.

Melia, T. P., and W. P. Moffitt (1964), Secondary Nucleation from Aqueous Solution, Industrial \& Engineering Chemistry Fundamentals, 3(4), 313-317.

Mullin, J. W. (2001), Crystallization, Butterworth-Heinemann.

Mullin, J. W., and K. D. Raven (1962), Influence of Mechanical Agitation on the Nucleation of Some Aqueous Salt Solutions, Nature, 195(4836), 35-38.

Natarajan, V., P. Bishnoi, and N. Kalogerakis (1994), Induction phenomena in gas hydrate nucleation, Chemical Engineering Science, 49(13), 2075-2087.

Østergaard, K. K., R. Anderson, M. Llamedo, and B. Tohidi (2002), Hydrate phase equilibria in porous media: effect of pore size and salinity, Terra Nova, 14(5), 307-312.

Park, S.-H., and G. Sposito (2003), Do montmorillonite surfaces promote methane hydrate formation? Monte carlo and molecular dynamics simulations, The Journal of Physical Chemistry B, 107(10), 2281-2290.

Restagno, F., L. Bocquet, and T. Biben (2000), Metastability and Nucleation in Capillary Condensation, Physical Review Letters, 84(11), 2433-2436.

Riestenberg, D., O. West, S. Lee, S. McCallum, and T. J. Phelps (2003), Sediment surface effects on methane hydrate formation and dissociation, Marine Geology, 198(1-2), 181-190.

Ripmeester, J. A., and S. Alavi (2010), Molecular simulations of methane hydrate nucleation, ChemPhysChem, 11(5), 978-980.

Skovborg, P., H. J. Ng, P. Rasmussen, and U. Mohn (1993), Measurement of induction times for the formation of methane and ethane gas hydrates, Chemical Engineering Science, 48(3), 445-453.

Sloan, E., C. Koh, A. Sum, A. Ballard, G. Shoup, N. McMullen, J. Creek, and T. Palermo (2009), Hydrates: state of the art inside and outside flowlines, Journal of petroleum technology, 61(12), 89-94.

Sloan, E. D., and F. Fleyfel (1991), A molecular mechanism for gas hydrate nucleation from ice, AIChE Journal, 37(9), 1281-1292.

Sloan, E. D., and C. A. Koh (2008), Clathrate hydrates of natural gases, 3rd ed., CRC Press, Boca Raton.

Tajima, H., A. Yamasaki, and F. Kiyono (2004), Continuous formation of CO2 hydrate via a Kenics-type static mixer, Energy and Fuels, 18(5), 1451-1456.

Ting, H. S. U. H., and W. L. McCabe (1934), Supersaturation and crystal formation in seeded solutions, Industrial and Engineering Chemistry, 26(11), 1201-1207.

Tohidi, B., J. Yang, M. Salehabadi, R. Anderson, and A. Chapoy (2010), CO2 Hydrates could provide secondary safety factor in subsurface sequestration of $\mathrm{CO} 2$, Environmental science \& technology, 44(4), 1509-1514.

Turnbull, D., and B. Vonnegut (1952), Nucleation catalysis, Industrial \& Engineering Chemistry, 44(6), 1292-1298.

Vysniauskas, A., and P. R. Bishnoi (1983), A kinetic study of methane hydrate formation, Chemical Engineering Science, 38(7), 1061-1072.

Walsh, M. R., C. A. Koh, E. D. Sloan, A. K. Sum, and D. T. Wu (2009), Microsecond simulations of spontaneous methane hydrate nucleation and growth, Science, 326(5956), 1095-1098.

Yun, T. S., J. C. Santamarina, and C. Ruppel (2007), Mechanical properties of sand, silt, and clay containing tetrahydrofuran hydrate, J. Geophys. Res., 112, B04106, doi:10.1029/2006JB004484.

Young, S. W. (1911), Mechanical stimulus to crystallization in supercooled liquids, Journal of the American Chemical Society, 33(2), 148-162.

Young, S. W., and R. J. Cross (1911), The mechanical stimulus to crystallization, Journal of the American Chemical Society, 33(8), 1375-1388. 
Table 1. Physical properties of selected sediments

\begin{tabular}{l|cccccc}
\hline & $\begin{array}{c}\text { Kaolinite } \\
(\mathrm{SA} 1)\end{array}$ & $\begin{array}{c}\text { Kaolinite } \\
(\mathrm{RP} 2)\end{array}$ & $\begin{array}{c}\text { Precipitated silt } \\
(\mathrm{PS})\end{array}$ & $\begin{array}{c}\text { Crushed silt } \\
(\mathrm{CS})\end{array}$ & $\begin{array}{c}\text { Ground } \mathrm{CaCO}_{3} \\
(\mathrm{GCC})\end{array}$ & $\begin{array}{c}\text { Precipitated } \mathrm{CaCO}_{3} \\
(\mathrm{PCC})\end{array}$ \\
\hline Specific gravity, $G s$ & 2.6 & 2.6 & 2.08 & 2.65 & 2.71 & 2.71 \\
Mean grain size, $d_{50}[\mu \mathrm{m}]$ & 1.1 & 0.36 & 20 & 20 & 12 & 1 \\
pH & 6.5 & 4.66 & 7 & 7 & 8.76 & 9.87 \\
Specific surface, $S_{s}\left[\mathrm{~m}^{2} / \mathrm{g}\right]$ & 36 & 29 & 120 & 0.113 & 1.8 & 9.9 \\
Liquid limit, $L L$ & 43 & 78 & - & - & 28 & 52 \\
Sphericity, $S$ & 0.7 & 0.7 & 0.9 & 0.9 & 0.8 & 0.2 \\
Roundness, $R$ & 0.1 & 0.3 & 0.7 & 0.1 & 0.5 & 0.9 \\
\hline
\end{tabular}


Figure 1. Schematic temperature-time signature corresponding to an exothermic phase transformation during cooling - Labels denote supercooling, induction time, freezing point depression, and equilibrium temperature.

Figure 2. Experimental configuration: (a) static test and (b) vibration test. Components: 1. 354 Piezoelectric actuator (Model 712A01, PCB Piezotronics, Inc.). 2. Accelerometer (Model 355 350B04, PCB Piezotronics, Inc.). 3. Nylon coupler. 4. Thermocouple (K-type, precision $\left.356=0.1^{\circ} \mathrm{C}\right) .5$. Heat-insulation foam cover. 6 . Stainless steel rod.

Figure 3. Phase transformation. (a) Stability temperature for THF-water mixtures at atmospheric pressure. (b) Typical temperature-time signatures for tap water, THF 360 solution with excess water $\left(90 \mathrm{H}_{2} \mathrm{O}: 10 \mathrm{THF}\right)$, stoichiometric mixture $100 \%$ hydrate

Figure 4. Effect of mineral grain characteristics on induction time. kaolinite (SA1), 364 kaolinite (RP2), precipitated silt (PS), crushed silt (CS), ground $\mathrm{CaCO}_{3}(\mathrm{GCC})$, $\left(81 \mathrm{H}_{2} \mathrm{O}: 19 \mathrm{THF}\right)$, and THF solution with excess THF $\left(40 \mathrm{H}_{2} \mathrm{O}: 60 \mathrm{THF}\right)$.

Figure 5. Experimental results in tripartite: (a) water to ice and (b) stoichiometric THF-water to hydrate transition. Induction times are represented by symbols: in (a) crosses are results of $t_{\text {ind }}<2500 \mathrm{~s}$ and circles are results of $t_{\text {ind }}>2500 \mathrm{~s}$; in (b) crosses are results of $t_{\text {ind }}<5000 \mathrm{~s}$ and circles are results of $t_{\text {ind }}>5000 \mathrm{~s}$.

Figure 6. Experimental results: Induction time $t_{\text {ind }}$ versus peak acceleration $a$. Cases: (a) tap water and (b) stoichiometric mixture $\left(81 \mathrm{H}_{2} \mathrm{O}: 19 \mathrm{THF}\right) 100 \%$ hydrate. Discrete points are experimental results obtained with mechanical vibrations. As a reference, the mean and standard deviation values of 16 specimens without vibration are shown as solid and dashed lines. 


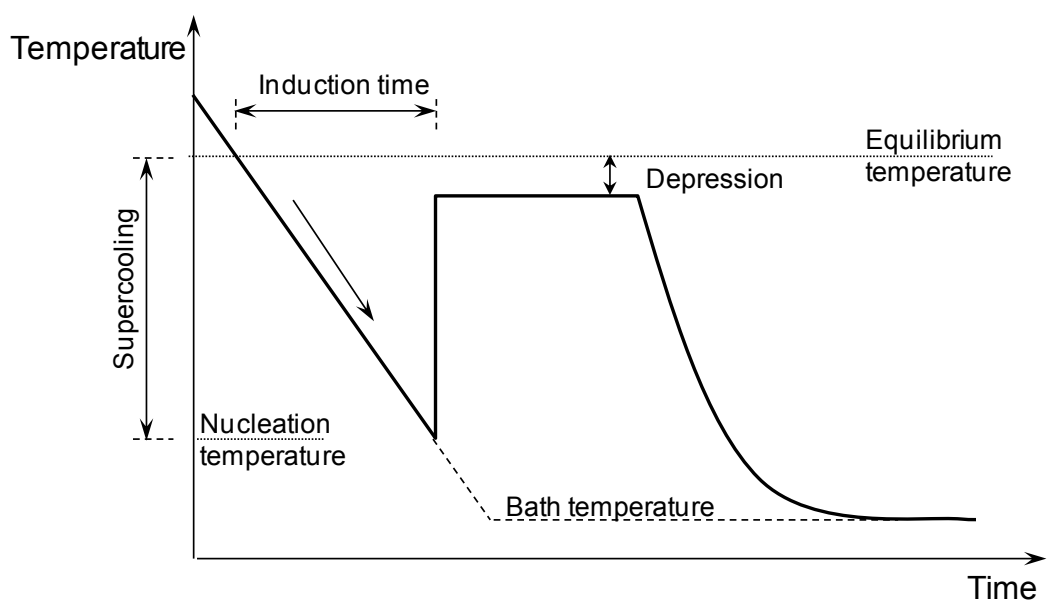

Figure 1. Schematic temperature-time signature corresponding to an exothermic phase transformation during cooling - Labels denote supercooling, induction time, freezing point depression, and equilibrium temperature. 
(a)

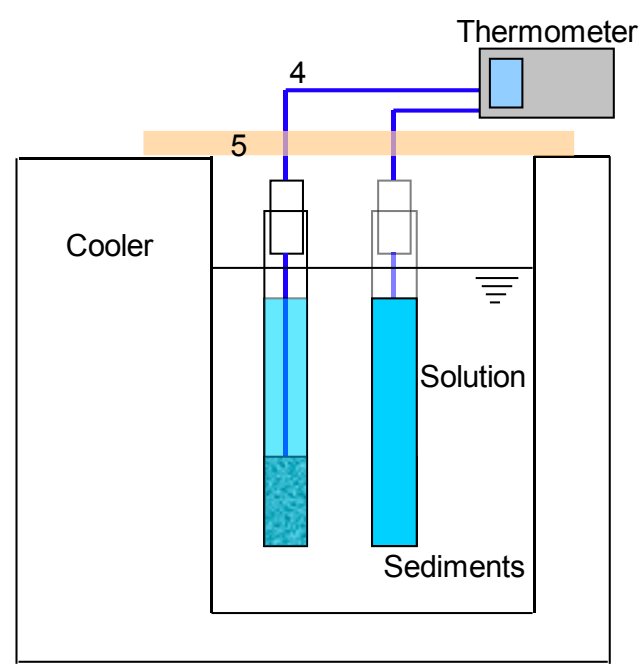

(b)
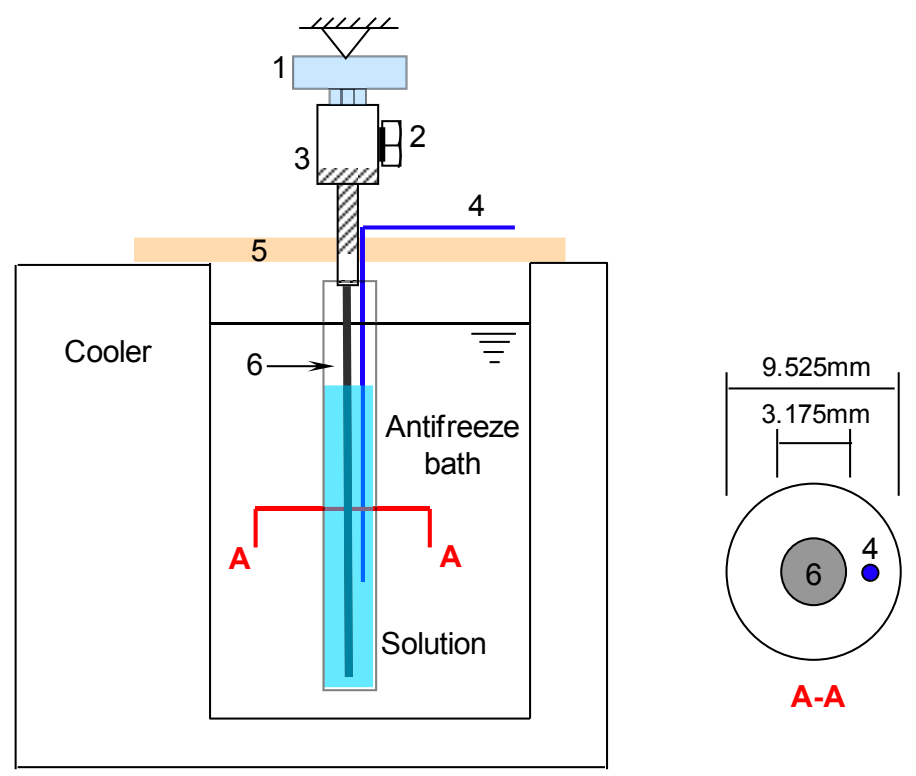

Figure 2. Experimental configuration: (a) static test and (b) vibration test. Components: 1. Piezoelectric actuator (Model 712A01, PCB Piezotronics, Inc.). 2. Accelerometer (Model 350B04, PCB Piezotronics, Inc.). 3. Nylon coupler. 4. Thermocouple (K-type, precision $\left.\mid=0.1^{\circ} \mathrm{C}\right) .5$. Heat-insulation foam cover. 6 . Stainless steel rod (100mm in length). 
(a)

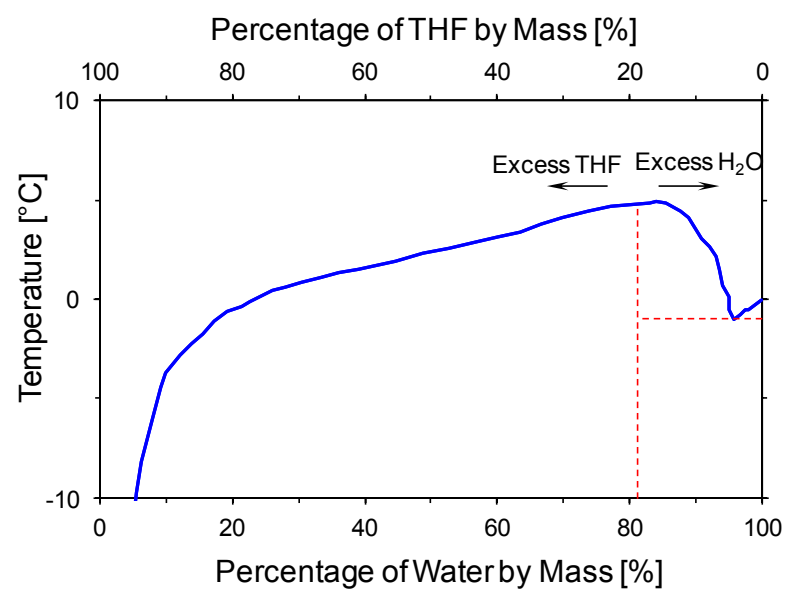

(b)

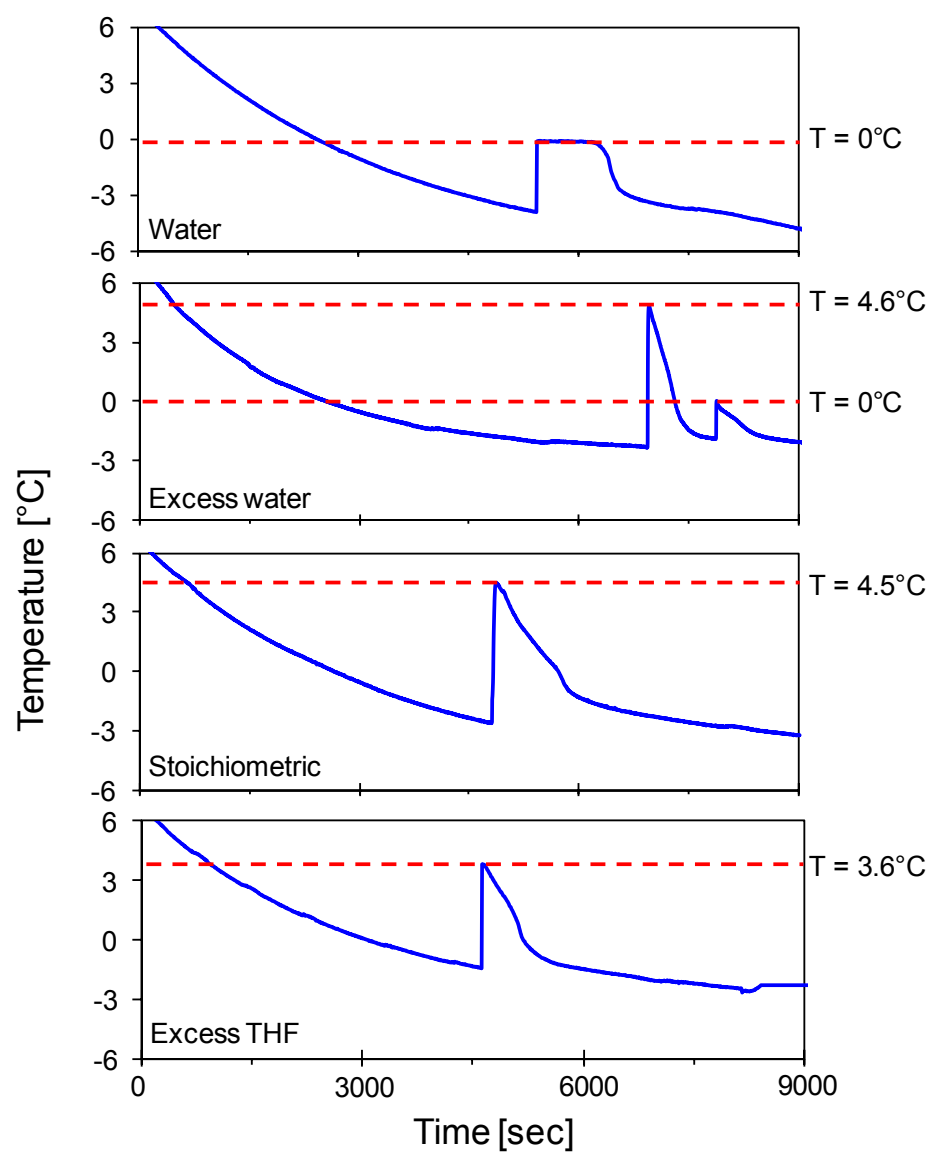

Figure 3. Phase transformation. (a) Stability temperature for THF-water mixtures at atmospheric pressure. (b) Typical temperature-time signatures for tap water, THF solution with excess water $\left(90 \mathrm{H}_{2} \mathrm{O}: 10 \mathrm{THF}\right)$, stoichiometric mixture $100 \%$ hydrate $\left(81 \mathrm{H}_{2} \mathrm{O}: 19 \mathrm{THF}\right)$, and THF solution with excess THF $\left(40 \mathrm{H}_{2} \mathrm{O}: 60 \mathrm{THF}\right)$. 


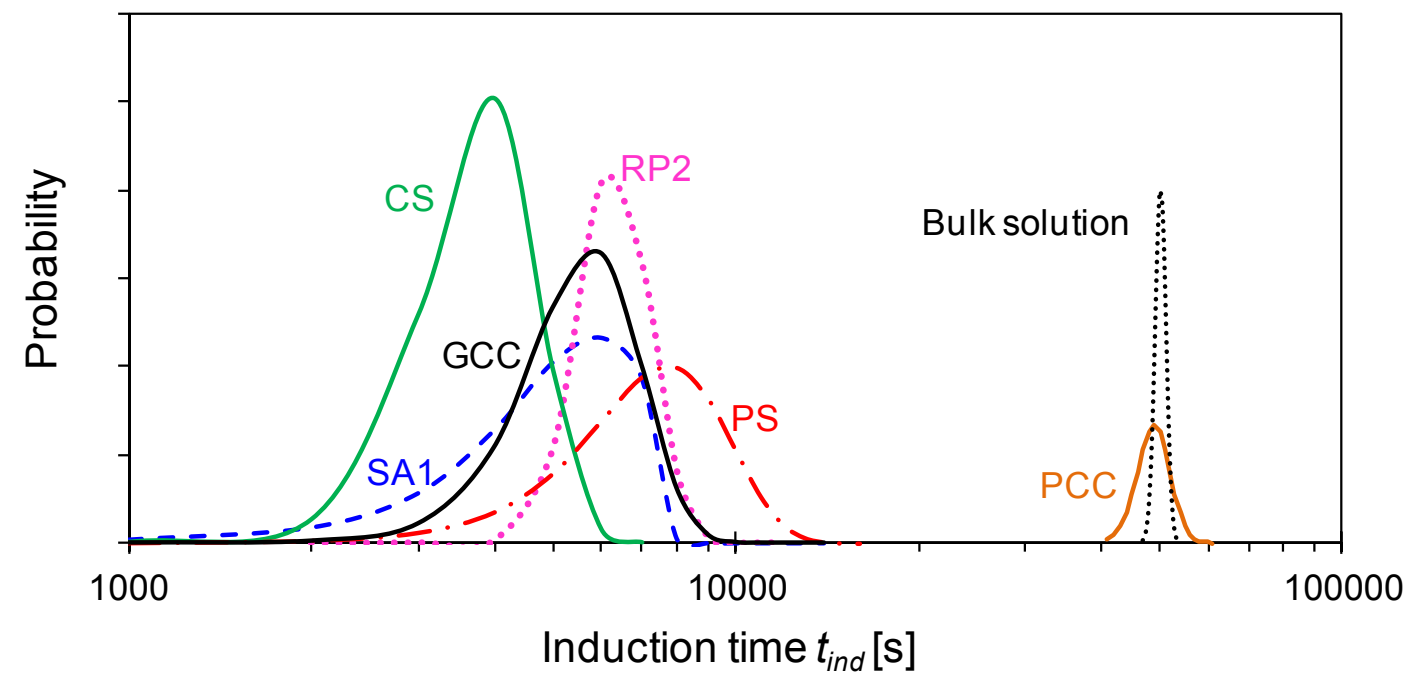

Figure 4. Effect of mineral grain characteristics on induction time. kaolinite (SA1), kaolinite (RP2), precipitated silt (PS), crushed silt (CS), ground $\mathrm{CaCO}_{3}$ (GCC), precipitated $\mathrm{CaCO}_{3}(\mathrm{PCC})$ 
(a)

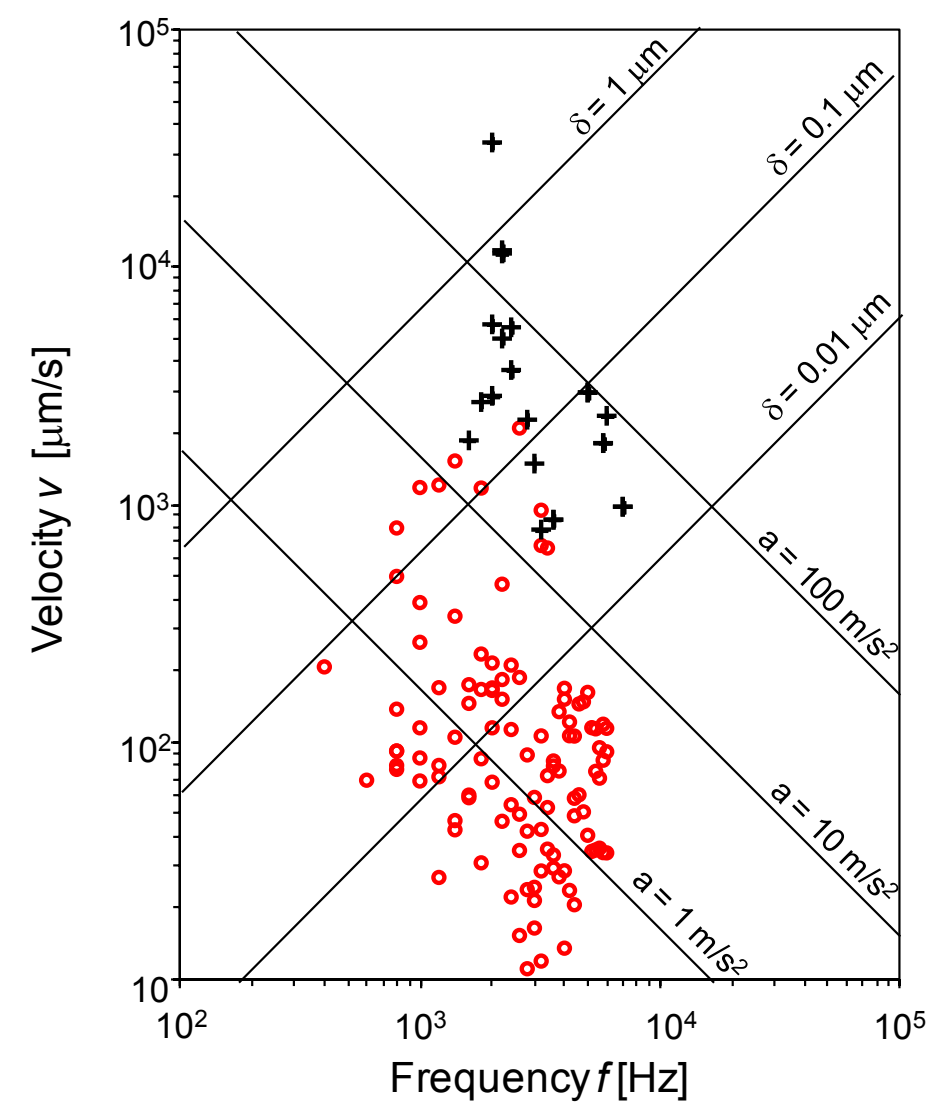

(b)

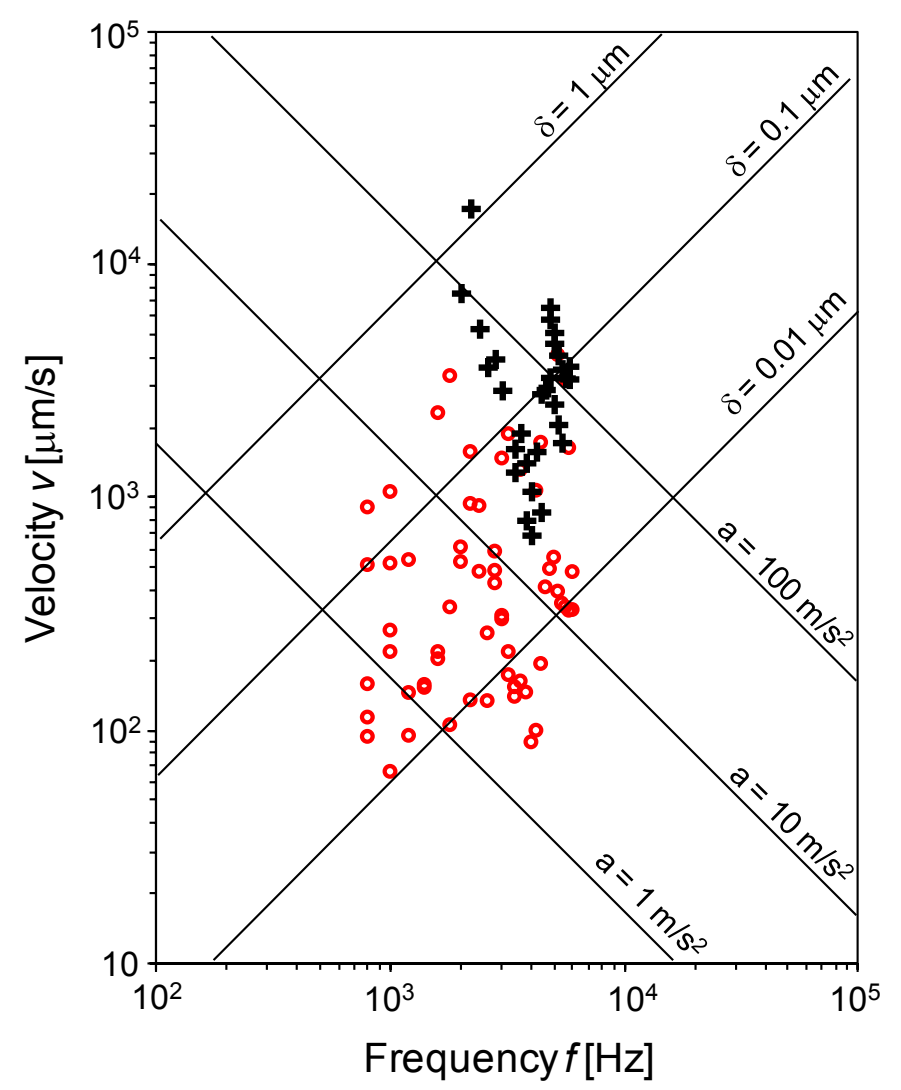

Figure 5. Experimental results in tripartite: (a) water to ice and (b) stoichiometric THF-water to hydrate transition. Induction times are represented by symbols: in (a) crosses are results of $t_{\text {ind }}<2500 \mathrm{~s}$ and circles are results of $t_{\text {ind }}>2500 \mathrm{~s}$; in (b) crosses are results of $t_{\text {ind }}<$ $5000 \mathrm{~s}$ and circles are results of $t_{\text {ind }}>5000 \mathrm{~s}$. 
(a) Water to ice
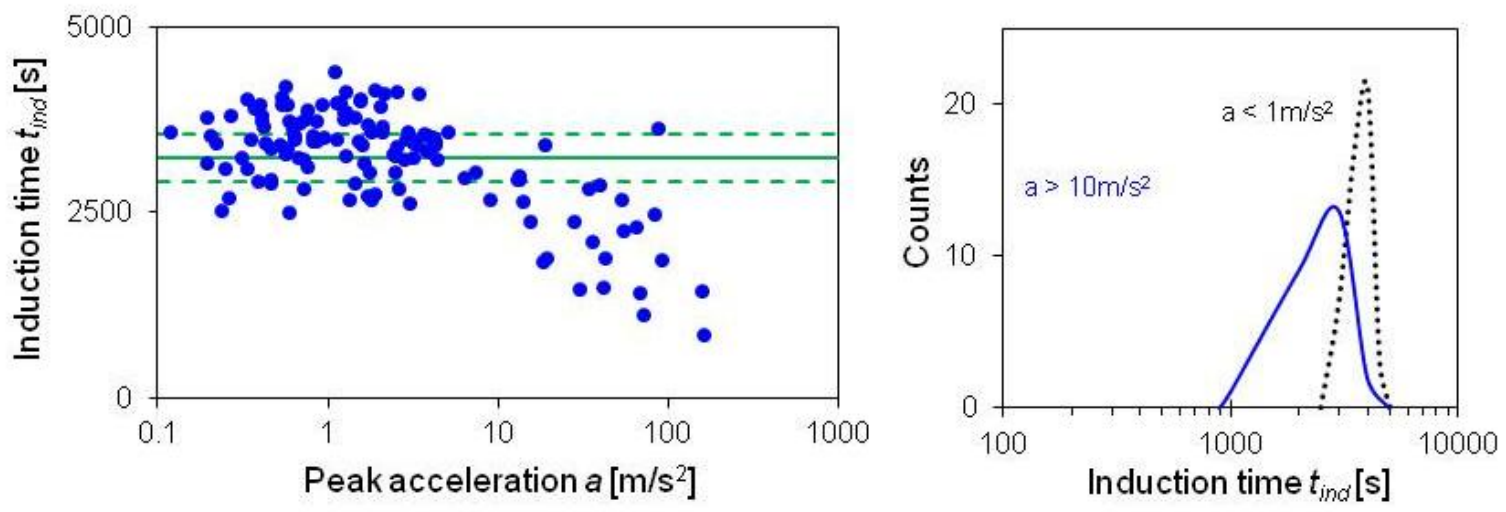

(b) Stoichiometric $\mathrm{H}_{2} \mathrm{O}$-THF mixture to THF hydrate
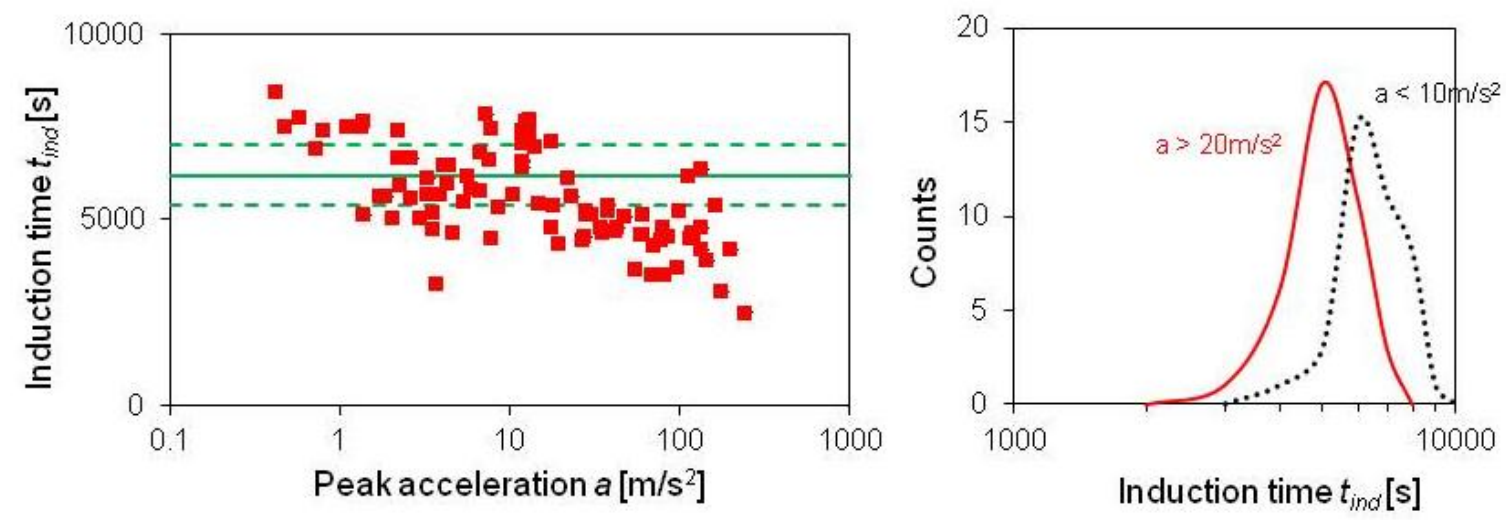

Figure 6. Experimental results: Induction time $t_{\text {ind }}$ versus peak acceleration $a$. Cases: (a) tap water and (b) stoichiometric mixture $\left(81 \mathrm{H}_{2} \mathrm{O}: 19 \mathrm{THF}\right) 100 \%$ hydrate. Discrete points are experimental results obtained with mechanical vibrations. As a reference, the mean and standard deviation values of 16 specimens without vibration are shown as solid and dashed lines. 